\title{
Conjuntivite por Achromobacter xylosoxidans: relato de caso
}

\author{
Conjunctivitis due to Achromobacter xylosoxidans: case report
}

\author{
Juliana Faggion Lucatelli ${ }^{1}$ \\ Vlademir Vicente Cantarelli ${ }^{2}$ \\ Simone Ulrich Picoli ${ }^{3}$
}

Trabalho realizado no Centro Universitário Feevale, Novo Hamburgo (RS) - Brasil.

${ }^{1}$ Biomédica do Centro Universitário Feevale, Novo Hamburgo (RS) - Brasil.

${ }^{2}$ Professor Adjunto do Centro Universitário Feevale, Novo Hamburgo (RS) - Brasil. Gerente Técnico de Microbiologia \& Biologia Molecular do Weinmann Laboratório, Porto Alegre (RS) - Brasil.

${ }^{3}$ Professora Adjunta do Centro Universitário Feevale, Novo Hamburgo (RS) - Brasil.

Endereço para correspondência: Simone Ulrich Picoli. Centro Universitário Feevale - Laboratório de Biomedicina - RS 239, $\mathrm{n}^{\circ} 2.755$ - Novo Hamburgo (RS) CEP 93352-000

E-mail: simonepi@terra.com.br

Recebido para publicação em 16.10.2007

Última versão recebida em 16.08.2008

Aprovação em 20.08.2008

\begin{tabular}{|c|}
\hline RESUMO \\
\hline Relatamos um caso de conjuntivite ocasionada por Achromobacter \\
xylosoxidans em paciente imunocompetente usuária de lentes de contato \\
rígidas. A bactéria foi isolada da solução utilizada para a desinfecção \\
das lentes bem como do raspado conjuntival. A. xylosoxidans tem sido \\
descrita em infecções oportunistas em pacientes imunodeprimidos, con- \\
tudo pode ser confundida com outros bacilos gram-negativos, princi- \\
palmente Pseudomonas aeruginosa, isoladas de infecções oculares em \\
pacientes imunocompetentes. Devido ao reduzido perfil de sensibilidade \\
aos antimicrobianos demonstrado pelo A. xylosoxidans, torna-se impor- \\
tante a identificação deste agente etiológico em quadros de conjuntivite. \\
\hline
\end{tabular}

Descritores: Achromobacter xylosoxidans/isolamento \& purificação; Conjuntivite; Lentes de contato; Soluções para lentes de contato; Infecções oculares bacterianas; Relatos de casos [Tipo de publicação]

\section{INTRODUÇÃ̃}

A bactéria Achromobacter xylosoxidans é um bacilo gram-negativo, não-fermentador de glicose. Pertence à microbiota humana, especialmente da pele e trato gastrintestinal ${ }^{(1)}$ e pode causar infecções oportunistas. A maioria dos relatos clínicos envolvendo esse microrganismo descreve infecções nosocomiais em pacientes imunodeprimidos e estão relacionadas à contaminação de líquidos e infusões.

Entre as infecções atribuídas à A. xylosoxidans, são descritas desde ceratoconjuntivite em pacientes imunodeprimidos até casos de bacteremia. Além disso, há raras descrições de úlcera de córnea em pacientes que usam lentes de contato gelatinosas. A incidência anual de ceratoconjuntivite bacteriana é bastante significativa entre usuários de lentes nos EUA e Reino Unido(2), contudo pode ser confundida com Pseudomonas aeruginosa e outros bacilos gram-negativos no desenvolvimento desta infecção. O grande problema do diagnóstico equivocado é que tais microrganismos têm comportamentos diferenciados frente aos antimicrobianos: Achromobacter é resistente às terapias convencionais, sendo de difícil erradicação e pode implicar até em intervenção cirúrgica (ceratoplastia).

\section{RELATO DO CASO}

Paciente feminina, 23 anos de idade, imunocompetente, usuária de lentes de contato há oito anos. Em 2007, quatro meses após ter aberto nova solução desinfetante para lentes de contato rígidas, começou a apresentar desconforto ao utilizar as mesmas. Relatou sensação de "areia nos olhos" e 
coceira tanto no uso quanto na ausência das lentes. Seguidos dois dias, começou a apresentar, também, fotossensibilidade e leve vermelhidão nos olhos, com ausência de secreção. Posteriormente, passou a lacrimejar muito e queixava-se de dificuldade em abrir os olhos devido à dor.

Em consulta ao oftalmologista foi diagnosticado acúmulo de proteína nas lentes de contato e recomendada descontinuação do uso das mesmas. Contudo, o quadro clínico de desconforto ocular permanecia presente, mesmo sem a utilização dessas. A paciente adquiriu novas lentes de contato descartáveis, contudo, após uma semana de uso, continuava com dores oculares, lacrimejamento intenso, seguido de perda visual momentânea. As novas lentes eram mantidas à noite na mesma solução de limpeza utilizada anteriormente. $\mathrm{Na}$ consulta de retorno ao oftalmologista, foi prescrito colírio de olopatadina cloridrato $0,2 \%$ (uma vez ao dia) e acetato de fluormetolona $0,1 \%$ (quatro vezes ao dia), para serem utilizados juntamente com as lentes de contato. Depois de cinco dias de uso desses medicamentos, as dores oculares, sensação de coceira e perda momentânea de visão não haviam cessado, contudo, biomicroscopicamente houve diminuição de papilas.

A fim de determinar a origem da infecção, o frasco com o produto para lavagem das lentes e raspado conjuntival foram encaminhados para análise microbiológica. Ambos foram semeados em ágar sangue, ágar chocolate e ágar MacConkey e incubados a $35^{\circ} \mathrm{C}$ por $24 \mathrm{~h}$. O crescimento de ambas amostras foi escasso no ágar MacConkey e abundante nos demais meios (Figura 1 e Figura 2). Foram empregados testes convencionais para sua identificação, como: coloração de gram (bacilo gramnegativo), teste de oxidase (positiva) e outras provas bioquímicas. Os resultados da identificação inicial foram inconclusivos e o isolado foi encaminhado para identificação molecular através da amplificação e sequenciamento do gene $16 \mathrm{~S}$ rRNA. O resultado indicou Achromobacter xylosoxidans. Apesar de não existir padronização de teste de sensibilidade aos antimicrobianos para esta bactéria (CLSI, 2007) ${ }^{(3)}$, foi realizado antibiograma empregando alguns discos testados em microrganismos não fermentadores. Nesse, a bactéria mostrou-se sensível apenas à ceftazidima e imipenem e resistente a amicacina, cefotaxima, gentamicina, norfloxacina.

Devido ao desconforto, dor e perturbação visual presentes na vigência do tratamento prescrito, a paciente procurou outro profissional para o qual apresentou os resultados da cultura de raspado conjuntival e da solução desinfetante de lentes. Na avaliação do segundo oftalmologista foi diagnosticada conjuntivite bacteriana. Em posse da identificação da bactéria, do resultado do antibiograma e do conhecimento que o emprego de acetato de fluormetolona $0,1 \%$ pode mascarar ou exacerbar doenças causadas por microrganismos, foi prescrito uso de colírio moxifloxacino cloridrato $0,5 \%$, uma das novas quinolonas, na posologia quatro vezes ao dia, por 14 dias. Na vigência deste tratamento a fotosensibilidade, ardência e vermelhidão cessaram, mas persistia a sensação de "areia nos olhos". O oftalmologista advertiu a paciente a procurá-lo caso algum dos outros sintomas

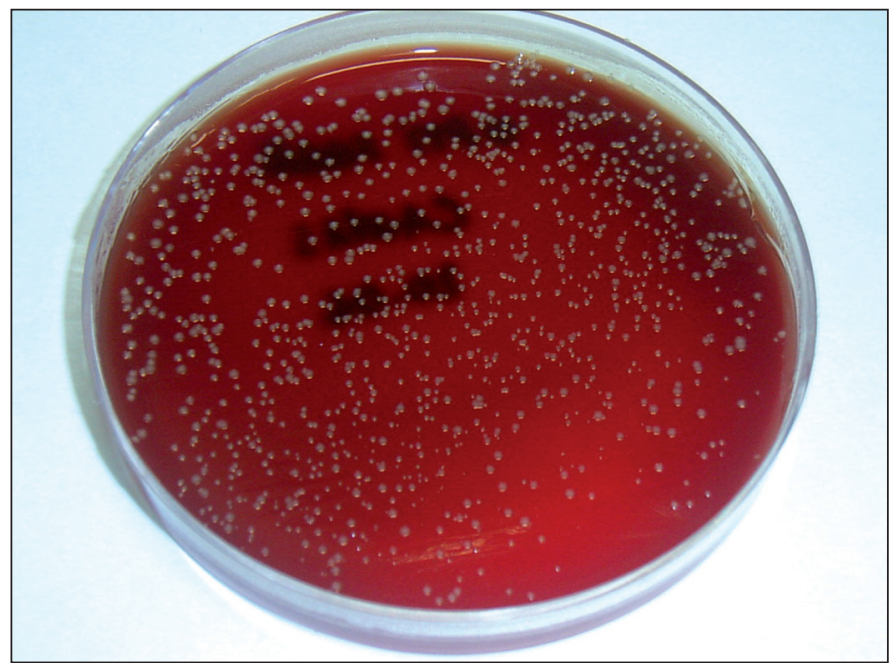

Figura 1 - Crescimento em agar sangue de carneiro $5 \%$

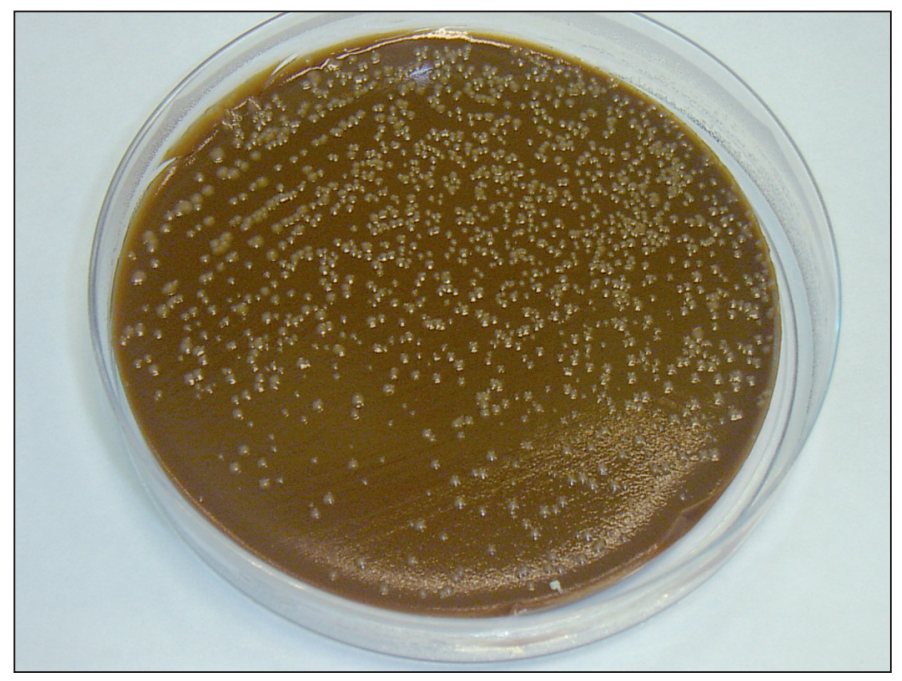

Figura 2 - Crescimento em agar chocolate

voltassem, para utilizar um colírio manipulado com o antimicrobiano adequado.

\section{DISCUSSÃO}

A incidência anual de ceratoconjuntivite bacteriana é significativa entre usuários de lentes de contato macias. Ocorre em 3,5 por 10.000 usuários diários das lentes e em 20 por 10.000 usuários de lentes por tempo prolongado ${ }^{(2)}$.

A. xylosoxidans é causa (rara) potencial de ceratite que não responde bem aos antimicrobianos. A maioria dos relatos clínicos envolvendo este microrganismo descreve infecções nosocomiais em imunodeprimidos devido à contaminação de transdutores de pressão intravenosa, solução de contraste, água deionizada, solução de clorexidina, desinfetantes, líquidos de diálise, solução salina e ventiladores mecânicos (revisado por Shie et al. 2005) $)^{(4)}$. 
Entre as infecções relacionadas à A. xylosoxidans são descritas bacteremia, meningite, pneumonia, empiema, abscesso pulmonar, peritonite, infecção do trato urinário, endocardite, artrite séptica, osteomielite, otite crônica, endolftalmite, infecção em pele/osso/junções e, ainda, ceratoconjuntivite em pacientes imunodeprimidos (revisado por Shie et al. 2005) ${ }^{(4)}$. Além disso, há raros casos de úlcera de córnea ocasionada por esta bactéria em pacientes que usam lentes de contato macias ${ }^{(5)}$.

Achromobacter está relacionado com essa infecção, porém é muito confundido com Pseudomonas aeruginosa, bactéria habitualmente associada à contaminação de produtos para lentes de contato ${ }^{(6)}$. Uma diferença importante entre esses microrganismos refere-se ao seu comportamento frente aos antimicrobianos. Achromobacter é geralmente sensível à carbenicilina, cefalosporinas de terceira geração, imipenem e sulfametoxazol-trimetoprim ${ }^{(7)}$ e resistente aos aminoglicosídeos, cefalosporinas de primeira e segunda geração, cloranfenicol e fluoroquinolonas ${ }^{(5)}$. Estudos mais recentes mostram que a bactéria pode não responder adequadamente à terapia antibiótica convencional com piperacilina ou ceftazidima (cefalosporina de terceira geração), sendo de difícil erradicação, implicando em necessidade de intervenção cirúrgica (ceratoplastia) ${ }^{(8)}$.

No caso descrito, houve equívoco no diagnóstico inicial e consequentemente o tratamento foi inadequado, gerando piora clínica, aumento na intensidade e no número de queixas oculares da paciente.

De acordo com o segundo oftalmologista, a paciente apresentava conjuntivite pela bactéria isolada a partir da solução de limpeza das lentes. Apesar do antibiograma de A. xylosoxidans mostrar perfil de resistência a vários antimicrobianos, inclusive à norfloxacino (fluoroquinolona), a conduta terapêutica com cloridrato de moxifloxacino (quinolona de quarta geração), demonstrou boa ação sobre a bactéria. Possivelmente isso possa ser atribuído ao seu melhor espectro de atuação em relação ao norfloxacino. O moxifloxacino é um agente antibacteriano fluoroquinolônico de amplo espectro e ação bactericida que possui atividade in vitro frente a uma ampla gama de microrganismos gram-positivos e gram-negativos, anaeróbios, bactérias ácido-resistentes e atípicas como Mycoplasma spp., Chlamydia spp. e Legionella $\mathrm{sp}^{(9)}$. Por outro lado, norfloxacino é mais indicado em infecções do trato genito-urinário, apresentado espectro de ação mais restrito ${ }^{(10)}$.

Segundo o CLSI (2007) ${ }^{(3)}$, não há padronização do teste de sensibilidade para bactérias gram-negativas não fermentadoras de glicose frente à moxifloxacino. Devem ser testadas apenas quinolonas como ciprofloxacino e levofloxacino. Segundo o oftalmologista, a eleição de moxifloxacino foi decorrente de ser o colírio antimicrobiano mais potente do mercado brasileiro, já que o medicamento com antibiótico adequado deveria ser manipulado e a demora poderia aumentar o quadro sintomático da paciente. Contudo, é relevante destacar que a terapia antimicrobiana deve ser sempre dirigida pelo resultado do antibiograma a fim de garantir erradicação da bactéria.

Em nova avaliação médica após término do tratamento com a referida quinolona, a única queixa da paciente era dis- creta sensação de "areia nos olhos". Tal sintoma foi considerado processo alérgico e foi tratado com aplicação de cloridrato de epinastina $0,05 \%$ por sete dias, culminando em cura clínica.

Diante do exposto, reafirma-se a relevância em conhecer o agente etiológico responsável por infecções oculares, oportunistas ou não, para o correto manejo do paciente. Se o tratamento for conduzido desconhecendo-se o microrganismo envolvido bem como sua susceptibilidade aos antimicrobianos, provavelmente não ocorrerá erradicação do processo infeccioso. Consequentemente se deve considerar a evolução desfavorável que poderá culminar em procedimento mais invasivo, como a intervenção cirúrgica ocular (ceratoplastia).

\section{ABSTRACT}

We report here a case of conjunctivitis in an immunocompetent patient due to Achromobacter xylosoxidans, which was associated with the use of rigid contact lenses. The bacteria were isolated from the scraped conjunctival swab as well as from the lens cleaning fluid. A. xylosoxidans is an opportunistic pathogen, especially in immunocompromised patients; however, in isolates of ocular infections, from immunocompetent patients, it may be confused with other gram-negative organisms, particularly Pseudomonas aeruginosa. Due to an increased resistance against different antimicrobial agents, $A$. xylosoxidans must be fully identified and differentiated from other gram-negative isolates from ocular infections.

Keywords: Achromobacter xylosoxidans/isolation \& purification; Conjunctivitis; Contact lenses; Contact lens solutions; Eye infections, bacterial; Case reports [Publication type]

\section{REFERÊNCIAS}

1. Wiatr M, Morawska A, Skladzien J, Kedzierska J. [Alcaligenes xylosoxidans-a pathogen of chronic ear infection]. Otolaryngol Pol. 2005;59(2):277-80. Polish.

2. Cheng KH, Leung SL, Hoekman HW, Beekhuis WH, Mulder PG, Geerards AJ, Kijlstra A. Incidence of contact-lens-associated microbial keratitis and its related morbidity. Lancet. 1999;354(9174):181-5. Comment in: Lancet. 1999; 354(9174):174-5. Lancet. 2000;355(9198):143-4.

3. Clinical and Laboratory Standards Institute. 2007. M100-S17. Performance standards for antimicrobial susceptibility testing; 16th informational supplement. Clinical and Laboratory Standards Institute, Wayne, PA.2007.

4. Shie SS, Huang CT, Leu HS. Characteristics of Achromobacter xylosoxidans bacteremia in northern Taiwan. J Microbiol Immunol Infect. 2005;38(4):277-82.

5. Fiscella R, Noth J. Achromobacter xylosoxidans corneal ulcer in a therapeutic soft contact lens wearer. Cornea. 1989;8(4):267-9.

6. Cohen EJ, Laibson PR, Arentsen JJ, Clemons CS. Corneal ulcers associated with cosmetic extended wear soft contact lenses. Ophthalmology. 1987;94(2):109-14.

7. Lin A, Driebe WT Jr, Polack P. Alcaligenes xylosoxidans keratitis post penetrating keratoplasty in a rigid gas permeable lens wearer. CLAO J. 1998; 24(4):239-41.

8. Huang ZL, Chen YF, Chang SW, Lin KK, Hsiao CH. Recurrent Alcaligenes xylosoxidans keratitis. Cornea. 2005;24(4):489-90.

9. Patrocínio JA, Garroté FIG, Patrocínio LG. Avaliação da eficácia e segurança do moxifloxacino por 7 dias no tratamento da rinossinusite aguda. Arqu Int Otorrinolaringol [Internet]. 2001;5(1). [citado 2007 Out 6]. Disponível em: http://www.arquivosdeorl.org.br/conteudo/acervo_port.asp?id=145>.

10. PDAMED. Guia Digital de Medicamentos Genéricos 2006. Norfloxacino[Internet]. [citado 2007 Out 6]. Disponível em: <http://www.pdamed.com.br/ genericos/pdamed_0001_0258_00600.php> 